\title{
Moralidad pública y efectos secundarios en la jurisprudencia reciente de la Corte Suprema de los Estados Unidos
}

\author{
Public morality and side effects in recent \\ U.S. Supreme Court case laws
}

Santiago Legarre*

Recepción: 8/6/2016

Evaluación: 18/11/2016

Aceptación final: 12/7/2017

\begin{abstract}
Resumen: El texto analiza la utilización de los argumentos de "moralidad pública" y "efectos secundarios" como justificación de la restricción de derechos constitucionales en la historia de la jurisprudencia de la Corte Suprema de Estados Unidos.
\end{abstract}

Palabras clave: moralidad pública, efectos secundarios, derechos fundamentales

\begin{abstract}
This article analyzes the use of "public morality" and "side effects" arguments as justification for the restriction of constitutional rights in the history of U.S. Supreme Court case laws.
\end{abstract}

Keywords: public morality, side effects, fundamental rights

* Profesor Titular de Derecho Constitucional, Universidad Católica Argentina. Investigador independiente del CONICET. Agradezco a Ricardo Guibourg, Greg Mitchell, Julieta Monteroni, Florencia Ratti e Iván Tolnay sus comentarios críticos. E-mail: santiagolegarre@uca.edu.ar 


\section{Introducción}

Para que en Estados Unidos la restricción de un derecho constitucional sea válida, debe estar fundada, al menos, en una base racional ${ }^{1}$; pero en algunos casos, debe existir, más aún, un interés estatal impostergable ${ }^{2}$. En línea afín de simplificación, la mera racionalidad de la restricción es requerida cuando el derecho en cuestión es una libertad constitucionalmente protegida; $y$, en cambio, el interés estatal impostergable se demanda cuando se trata de una libertad catalogada como "derecho fundamental" . Este es el abecé —o, más bien, una versión simplificada- de la sabiduría convencional.

Durante décadas sinnúmero, la moralidad pública fue considerada como una justificación válida de la restricción de derechos constitucionales (sin distinción entre libertades y derechos fundamentales). Cuando, durante la llamada "Era Lochner" (1905-1934) ${ }^{4}$, se pusieron exitosamente en tela de juicio otras justificaciones de la restricción de derechos constitucionales (como, por ejemplo, el bienestar económico) $)^{5}$, la moralidad pública salió, en cambio, siempre airosa ${ }^{6}$.

1 Cuando basta una base racional, es el sujeto que ataca la norma quien tiene la carga de probar que la relación entre medios y fines no existe. Véase, por ejemplo, la doctrina de la Corte Suprema de los Estados Unidos registrada paradigmáticamente en 291 U.S. 502 (1934) y 300 U.S. 379 (1937).

2 En estos casos, es el gobierno quien debe demostrar que la restricción del derecho fundamental está estrechamente ajustada a la promoción de un interés social impostergable [narrowly tailored to promote a compelling state interest]. Véase, por ejemplo, la doctrina de la Corte Suprema de los Estados Unidos registrada paradigmáticamente en 410 U.S. 113 (1973).

3 Para la distinción entre libertad constitucional y derecho fundamental, véase, por ejemplo, Nowak, J.E. y Rotunda, R.D., Constitutional Law, Octava edición, West Group, St. Paul, Minnesota, 2010, ps. 489-492.

4 Así llamada por el caso registrado en 198 U.S. 45 (1905).

5 Véase, por ejemplo, Tribe, L. H., American Constitutional Law, Tercera edición, Foundation Press, New York, 2000, Vol. I, pp. 1348-1350.

6 La "Era Lochner" supuso una revolución judicial de cara a los derechos económicos, pero no afectó la deferencia de la Corte hacia las llamadas morals laws. Como afirma Wolfe, "el poder de regular la moralidad permaneció como una parte firmemente establecida del derecho americano hasta bien entrado el siglo veinte". Wolfe, C., "Public Morality and the Modern Supreme Court", 45 American Journal of Jurisprudence 65, 2000, pág. 71. 
Moralidad pública y efectos secundarios en la jurisprudencia reciente...

A partir de los años sesenta, con la llamada "Era Moderna" y el advenimiento de Earl Warren a la presidencia de la Corte Suprema de los Estados Unidos ${ }^{7}$, el reinado de la moralidad pública como causal de justificación válida de derechos entró en crisis $^{8}$, de la mano del afinamiento del doble estándar de revisión judicial de los actos restrictivos de derechos que recordé anteriormente: si una libertad era reconocida por la Corte como "derecho fundamental", entonces era harto probable que la moralidad pública no calificara como interés estatal impostergable ${ }^{9}$. Sin embargo, cuando, por tratarse de una simple libertad constitucionalmente protegida, la exigencia fuera meramente la de una base racional para la legislación restrictiva ${ }^{10}$, la moralidad pública sobreviviría los embates, inclusive durante la "Era Moderna"11. $\mathrm{O}$ al menos esto era así hasta cierta línea jurisprudencial que examinaré en esta nota ${ }^{12}$, después de la cual, la afirmación precedente resulta menos clara...

7 Por eso, a veces se habla de la "Corte Warren", que debe su apelativo a Earl Warren, quien fuera su Chief Justice entre 1953 y 1969.

8 Cito nuevamente a Wolfe, quien afirma que en los años de la "Corte Warren" (la "Era Moderna") se dio "una oposición sistemática y extendida, no tanto a este o aquel ejercicio del poder de regular la moralidad en particular sino al principio fundamental de la regulación legal de la moralidad". Wolfe, op. cit., pág. 71.

9 Un ejemplo claro de esto es el famoso fallo Roe v. Wade, 410 U.S. 113 (1973).

${ }^{10}$ Por supuesto, cuando una determinada conducta no solamente es desconocida como un derecho fundamental sino que ni siquiera califica como libertad constitucionalmente protegida — en otras palabras, es conducta no protegida constitucionalmentepuede a fortiori ser válidamente restringida por razones de moralidad pública. Véase, por ejemplo, el voto del juez Easterbrook en el fallo de Cámara correspondiente al caso de Corte Barnes, al que se refiere la sección siguiente. Miller v. Civil City of South Bend 904 F.2d 1081, 1131 (1990, voto del juez Easterbrook). Véase también el voto del juez Scalia en el caso Barnes, infra, plenamente en sintonía con el de Easterbrook en la instancia anterior.

${ }^{11}$ En autorizadas palabras del Justice Thurgood Marshall, "[...] las meras preferencias o creencias legislativas respecto de cuestiones de conveniencia pública pueden perfectamente fundamentar regulaciones destinadas a otras actividades personales [que no constituyan un derecho fundamental]". California v. LaRue, 409 U.S. 109, 131 (1972), voto en disidencia de Marshall, con cita de Schneider v. State, 308 U.S. 147, 161 (1939).

${ }^{12}$ Los tres fallos que analizaré a continuación se dictaron entre 1991 y 2002. Si bien no son en modo alguno antiguos, podría considerárselos no recientes. Cabe hacer notar 


\section{La aparente sustitución del estándar de la moralidad pública por el de los efectos secundarios}

\section{II.1 El caso Barnes v. Glen Theater (1991)}

En 1991, en plena "Era Moderna", la Corte Suprema de los Estados Unidos resolvió un caso capital para la determinación de la suerte y el alcance de la moralidad pública como causa de restricción válida de derechos constitucionales. Los hechos sucedieron en la década de los ochenta, en un pueblo del estado de Indiana llamado South Bend, donde queda la University of Notre Dame, dicho sea de paso, a título anecdótico. Sintéticamente, esto fue lo sucedido, tal como lo relata la propia Corte:

"E1 [establecimiento] 'Kitty Kat' está ubicado en la ciudad de South Bend. Expende bebidas alcohólicas y exhibe baile 'a go-go'. Su propietario desea exhibir 'baile totalmente desnudo' pero una ley aplicable de Indiana que regula la desnudez pública exige que las bailarinas usen 'tapitas' [pasties] y una 'tanga' [G-string] cuando bailan. [...] Darlene Miller, una de las apeladas en la acción, había trabajado en el 'Kitty Kat' por casi dos años al tiempo en que se presentó esta acción. Miller desea bailar desnuda [...].

La apelada 'Glen Theatre' es una empresa de Indiana con un local en South Bend. Su principal cometido es suministrar entretenimientos para adultos mediante material escrito e impreso, exhibiciones de películas y entretenimiento en vivo en una 'librería' aledaña. Este último consiste en actuaciones desnudas y semidesnudas y exhibiciones del cuerpo desnudo a través de paneles de vidrio"13.

que las sentencias sobre este tema dictadas por la Corte Suprema de Estados Unidos con posterioridad a 2002 son escasas y carecen de aportes doctrinales relevantes.

${ }^{13}$ Barnes v. Glen Theater, 501 U.S. 560, 563 (1991). El caso está publicado en español en la revista E1 Derecho, 1992, 148-594, con notas de G. J. Bidart Campos y W. F. Carnota. En Estados Unidos, el comentario más exhaustivo de este fallo es el del profesor de la Universidad de Columbia, Vincent Blasi. Ver: Blasi, V., "Six Conser- 
Moralidad pública y efectos secundarios en la jurisprudencia reciente...

El establecimiento Kitty Kat, el teatro Glen y la bailarina Miller iniciaron una demanda contra el estado de Indiana, con la finalidad de impedir que se les aplicara la ley estatal de indecencia pública. Luego de un procedimiento largo y varias sentencias de primera y segunda instancia, la Corte Suprema de los Estados Unidos resolvió la cuestión por cinco votos contra cuatro en una causa que en la instancia máxima fue caratulada como Barnes v. Glen Theatre ${ }^{14}$.

La mayoría resolvió que la aludida ley de Indiana de indecencia pública, en cuanto establecía limitaciones para el baile desnudo en establecimientos eróticos, no violaba la Constitución, a pesar de reconocer que ese tipo de baile gozaba de cierta protección constitucional a la luz de la Enmienda Primera; o, en otras palabras, a pesar de reconocer que se trataba de una libertad constitucionalmente protegida (sin llegar a constituir un "derecho fundamental").

Sin embargo, los jueces que formaron la mayoría no votaron todos juntos: el presidente, Rehnquist, escribió un voto ("opinion", se dice en inglés) para la Corte, al que adhirieron los Justices O’Connor y Kennedy - y ninguno más- Los jueces Scalia y Souter escribieron votos ("opinions") concurriendo en el judgment (el segmento resolutivo de la sentencia) propuesto por el Chief Justice Rehnquist, pero por sus propios argumentos. El resultado de esto fue que el voto del presidente se convirtió, tan solo, en una "plurality opinion"15: el voto concurrente de una pluralidad. En otras palabras, no fue el voto de una mayoría.

Justice White escribió un voto disidente: una "dissenting opinion". Es decir, no estuvo de acuerdo ni con la opinion for the Court ni con

vatives in Search of the First Amendment: the Revealing Case of Nude Dancing", 33 William and Mary Law Review 611, 1992. Este trabajo incluye interesantes datos biográficos de los jueces Posner y Easterbrook — quienes intervinieron en la sentencia de la Cámara Federal de Apelaciones para el Séptimo Circuito en este causa- y de los cuatro Justices de la Corte Suprema que escribieron votos en Barnes (Rehnquist, Scalia, Souter y White).

14501 U.S. 560 (1991). En segunda instancia, el caso se había llamado Miller v. Civil City of South Bend, por el nombre de una de las bailarinas demandantes.

${ }^{15}$ Las plurality opinions, si bien no constituyen un precedente stricto sensu $-\mathrm{y}$ por tanto no obligan a los tribunales a stare decisis-, pueden llegar a tener una fuerza persuasiva importante. 
el judgment of the Court. Adhirieron al voto de White los jueces Marshall, Blackmun y Stevens. Para ellos, "el baile desnudo no-obsceno llevado a cabo como entretenimiento público es conducta expresiva protegida por la Primera Enmienda"16; y, frente a este "derecho fundamental", la moralidad pública no es justificación suficiente: "la simple referencia al interés general del Estado en promover el orden social y la moralidad no es justificación suficiente para una ley que, según se ha concedido, impacta sobre una cantidad significativa de actividad expresiva protegida" 17 .

De regreso con la mayoría, la pluralidad de Justices que votó en primer término consideró, entre otras cosas, que "la finalidad de la ley de proteger el orden social y la moralidad resulta clara a partir de su texto y de su historia"18, y que esta ley, al igual que otras semejantes, "fue diseñada para proteger la moral [morals] y el orden público [public order]"19. A continuación, con palabras que ratificaban la vigencia en la "Era Moderna" del rationale de la moralidad pública (en ausencia de un "derecho fundamental"), la pluralidad expresó que "el tradicional poder de policía de los estados es definido como la autoridad para proveer lo conducente a la salud, la seguridad y la moral públicas, y hemos sostenido tal fundamento para la legislación"20.

El cuarto juez que integró la mayoría, Scalia, votó por separado pues el baile en cuestión carece de protección constitucional, según su criterio. Para Justice Scalia, en este caso no se encuentra en juego la libertad de expresión porque la ley cuestionada es "una ley general reguladora de conducta y no específicamente dirigida contra expresión"21; por tanto, "no está sujeta en absoluto a escrutinio a la luz de la Primera Enmienda [First-Amendment scrutiny]"22. Insiste este juez:

16 Barnes, 587, voto en disidencia del juez White.

${ }^{17}$ Barnes, 590, voto en disidencia del juez White.

18 Barnes, 568.

19 Barnes, 569.

${ }^{20}$ Barnes, 569, con cita de Paris Adult Theatre I v. Slaton, 413 U.S. 49, 61 (1973), entre otros.

21 Barnes, 572, voto concurrente de Scalia.

${ }^{22}$ Barnes, 572. Lo reitera Scalia con claridad más adelante: "Dado que la reglamentación de Indiana es una ley general que no apunta específicamente contra conducta 
Moralidad pública y efectos secundarios en la jurisprudencia reciente...

"La ley de Indiana se halla en la misma línea de una larga tradición de leyes contra la desnudez pública de las cuales nunca se pensó que fueran contrarias al entendimiento tradicional de la 'libertad de palabra' ['freedom of speech']"23. Es una ley general, que tiene por fin proteger la moralidad pública ${ }^{24}$ —ofendida por la desnudez pública, a criterio de la ley-y no, en cambio, excluir el mensaje erótico de las bailarinas desnudas, exclusión que constituye un efecto incidental del medio elegido. Dado que la moralidad pública había sido sostenida reiteradamente por la Corte como "base racional" [rational basis] para la prohibición de conducta que no constituyera un derecho fundamental, Justice Scalia arriba a la misma conclusión que la pluralidad: la ley de Indiana no ofrece reparos constitucionales. Y lo hace, por lo visto, por un camino no muy distinto, en cierto aspecto, al de la pluralidad.

El juez que aportó el quinto voto, Souter, estuvo, en cierto sentido, más cerca de la pluralidad que Scalia; y en cierto sentido estuvo más lejos. Digo lo primero, porque al igual que para la pluralidad, para Souter el baile desnudo tiene cierta protección constitucional, aunque no sea un "derecho fundamental" 25 . Digo lo segundo, porque para Souter el método de la pluralidad de justificar la restricción de esa "libertad constitucionalmente protegida que no llega a ser un derecho fundamental" - el método de usar el rationale de la moralidad pública- debía ser sustituido por otro método (que lo aleja aparentemente, también, del criterio de Scalia, como veremos): el método de los "efectos secundarios" (a los que se refiere el título de mi trabajo).

En sus propias palabras, Souter escribe separadamente:

para apoyar mi concurrencia en el resultado [concurrence in the judgment], no en la posible suficiencia de los pareceres

expresiva, su aplicación a ese tipo de conducta no trae a colación, en mi opinión, la aplicación de la Primera Enmienda" (íd., 576).

23 Barnes, 573, concurrencia de Scalia.

24 "E1 propósito de la ley de Indiana, como queda demostrado tanto por su texto como por la manera en que se la aplica, es asegurar la vigencia de la creencia moral tradicional de que la gente no debe exponer sus partes privadas indiscriminadamente [...]". Barnes, 575, concurrencia de Scalia.

25 Barnes, 581, concurrencia de Souter. 
morales de la sociedad para justificar las restricciones aquí en debate, sino en el interés sustancial del Estado en combatir los efectos secundarios de los establecimientos de entretenimiento para adultos como los tipificados por los establecimientos de las partes apeladas ${ }^{26}$.

Este "interés" había sido articulado por el estado apelante, cuando afirmó que la ley se aplicaba al baile desnudo porque dicho baile "favorece la prostitución, incrementa las ofensas sexuales y atrae otras actividades criminales" 27 . Según Justice Souter, el interés en prevenir todas estas actividades era suficiente para justificar la aplicación de la ley de indecencia pública contra este tipo de entretenimiento para adultos ${ }^{28}$.

Justice Souter, en suma, no está dispuesto a acompañar a la pluralidad con el rationale de la moralidad pública y prefiere transitar el camino de los efectos secundarios, aprovechando el hecho de que el estado de Indiana había articulado en esos términos el aludido interés. Sus palabras, transcriptas, no niegan que la moralidad pública pueda jugar un rol más allá de proveer una base racional en casos que no comprometen derechos fundamentales; su silencio, sin embargo, ha invitado a aventurar que existe una negativa de su parte.

El profesor Blasi, por ejemplo, interpreta que en Barnes Souter no acepta que la protección de la moralidad pública sea un interés "sustancial o importante". En efecto, Blasi considera que para este juez "posiblemente la exclusiva" base para restringir derechos de expresión protegidos por la Primera Enmienda sea la consideración de daños materiales ${ }^{29}$. También el profesor Cicchino pondera los alcances de la consideración distintiva del tema de los efectos secundarios en el voto de Justice Souter en Barnes, para contrastarla con los argumentos basados

${ }^{26}$ Barnes, 582, voto concurrente de Souter. Como remarcaré seguidamente en el texto, Justice Souter no dijo si la "posible suficiencia" del rationale de la moralidad pública era también suficiencia actual y efectiva; se contentó, en cambio, con transitar el camino de los "efectos secundarios".

${ }^{27}$ Barnes, 582, voto concurrente de Souter, con cita del Brief for Petitioners, un escrito presentado ante la Corte por el peticionante del certiorari (en este caso, el estado de Indiana).

${ }^{28}$ Barnes, 583, voto concurrente de Souter.

${ }^{29}$ Blasi, op. cit., pág. 652. 
Moralidad pública y efectos secundarios en la jurisprudencia reciente...

en consideraciones de moral pública, como los usados por la pluralidad (y por Scalia). A este autor, abiertamente crítico de la moralidad pública en este contexto, no le pasó inadvertido el diferente carril transitado por Justice Souter: "Los 'efectos secundarios' de Justice Souter [...] son precisamente los tipos de efectos empíricos sobre el bienestar público respecto de los cuales los argumentos de moralidad pública [...] están desconectados" ${ }^{\prime 3}$. Desde una perspectiva antitética, Wolfe, que simpatiza con la moralidad pública como rationale legislativo, también notó - en este caso, con preocupación — la particularidad del voto de Justice Souter en Barnes, al que llama el "quinto voto clave"31.

En suma, en Barnes v. Glen Theatre, se dio en la Corte Suprema una discusión que iba más allá de cabarés y bailarinas desnudas. Estaba en juego, sobre todo, la medida en que la moralidad pública justificaba la limitación de una actividad a la que se le había reconocido cierta tutela constitucional ${ }^{32}$. El presidente de la Corte invitó a sus colegas a responder con una medida generosa ${ }^{33}$; solo dos de ellos aceptaron su propuesta (O'Connor y Kennedy). Un tercero, Justice Scalia, no tuvo inconveniente en abrazar con amplitud el rationale de la moralidad pública, pero los alcances de su criterio son difíciles de medir ya que trató al caso como si la Primera Enmienda no hubiera estado involucrada - como si se tratara de conducta sin protección constitucional específica alguna-. Justice Souter, el quinto en apoyar el judgment de la mayoría, no quiso pronunciarse sobre la efectiva suficiencia del rationale en cuestión. La disidencia, por su parte, lo cuestionó abiertamente como justificación para restringir expresión constitucionalmente protegida —o sea, un "derecho fundamental"—.

${ }^{30}$ Cicchino, P. M., "Reason and the Rule of Law: Should Bare Assertions of 'Public Morality' Qualify as Legitimate Government Interests for the Purposes of Equal Protection Review?" 87 Georgetown Law Journal 139, 1998, p. 170.

31 Wolfe, op. cit., p. 74.

32 Blasi lo ve con claridad en la obra citada, p. 612.

${ }^{33}$ Vuelvo a Blasi: “[...] Rehnquist trató de tomar ventaja de la ocasión para lograr que ganara aceptación la proposición de que la puesta en vigencia [enforcement] de la moral es una base apropiada para limitar la libertad de expresión. Su esfuerzo fue solo parcialmente exitoso: solamente los Justices Kennedy y O'Connor se unieron a la opinion de Rehnquist". Blasi, pág. 639. 
En suma, el estatus de la moralidad pública en casos difíciles, como este, no quedó totalmente definido. El fallo siguiente de esta saga arroja algo más de luz (y, según se vea, algo más de sombra).

\section{II.2 El caso City of Erie v. Pap's (2000)}

En septiembre de 1994, tres años después del caso Barnes, la ciudad de Erie, en el estado de Pennsylvania, sancionó una ordenanza mediante la cual se prohibía aparecer en público en un "estado de desnudez" 34 . Pap's era una empresa de Pennsylvania que operaba en Erie un local conocido como "Kandyland", el cual ofrecía espectáculos de baile femenino totalmente desnudo. Para cumplir con la nueva ordenanza, las bailarinas deberían usar, como mínimo, "tapitas" y "una tanga": en otras palabras, lo mismo que en Indiana a partir de la sanción de la ley que dio lugar al caso Barnes, analizado en la sección precedente. Pap's inició un juicio para evitar que la ordenanza se llegara a aplicar a Kandyland —una especie de amparo preventivo-, invocando una inminente violación de derechos fundados en la Primera Enmienda.

Luego de un litigio ante los tribunales inferiores, el caso llegó a la Corte Suprema de los Estados Unidos. Justice O'Connor, que llevó esta vez la voz cantante, comenzó por reconocer que "[s]i bien en Barnes analizamos una ley prácticamente idéntica [a la ordenanza de Erie], y sostuvimos que la prohibición de la desnudez pública impuesta por Indiana no violaba la Primera Enmienda, no existió acuerdo de cinco miembros de la Corte sobre un único rationale para esa conclusión" ${ }^{35}$. Con la finalidad de subsanar esta deficiencia de Barnes, Justice O'Connor invitó a sus colegas a evaluar nuevamente "las restricciones de la desnudez pública del tipo de la regulada por la ordenanza aquí en cuestión" 36 . Sin embargo, veremos que el encomiable esfuerzo en

\footnotetext{
${ }^{34}$ Los hechos están tomados del relato llevado a cabo por Justice O'Connor en City of Erie v. Pap's A.M., 529 U.S. 277, 283-284 (2000).

35 Erie, 278, opinion de la pluralidad, per Justice O'Connor. 
Moralidad pública y efectos secundarios en la jurisprudencia reciente...

acercar posiciones llevado adelante en Erie por quienes habían integrado la pluralidad de Barnes pudo haber arrastrado la debilitación de la moralidad pública como justificación de restricciones gubernamentales del tipo en cuestión.

En primer lugar, en sentido estricto Erie nos presenta una vez más una plurality opinion (y no el voto de una mayoría que califica como precedente), solo que esta vez en lugar de ser una pluralidad de tres, es una pluralidad de cuatro. Así, la opinion escrita por Justice O'Connor fue suscripta por Rehnquist y Kennedy (que también integraban la pluralidad de Barnes) y también por Breyer (que se sumó a la Corte luego de Barnes). Justice Souter no solamente se negó a firmar la opinion de la pluralidad sino que además disintió del judgment de la Corte, favorable a la constitucionalidad de la ordenanza de Erie. Su voto fue, por tanto, una concurrencia parcial y una disidencia parcial - aunque adelanto ya que Souter reitera aquí su adhesión al test de los efectos secundarios - ${ }^{37}$. Fueron los votos de los Justices Scalia y Thomas los que se sumaron a la pluralidad para definir el resultado del caso, aportando dos adhesiones al judgment (aunque por sus propias razones), que concitó, así, seis adhesiones ${ }^{38}$. Los Justices Stevens y Ginsburg, resta decir, votaron en disidencia total ${ }^{39}$.

${ }^{37}$ Erie, 310, voto de Souter, concurriendo en parte y disintiendo en parte. La reiteración en Erie del test de los efectos secundarios que Souter había anunciado en Barnes viene con algunos matices diferenciadores relevantes desde el punto de vista práctico, pero no para mi argumento aquí.

38 Erie, 302, voto de Scalia, concurriendo en el judgment. Scalia (a cuyo voto adhirió Justice Thomas) abordó la ordenanza de Erie como una típica norma de policía en materias morales: tal como lo habían hecho tanto la pluralidad como el propio Justice Scalia en Barnes.

${ }^{39}$ Erie, 317, voto en disidencia de Stevens, al que adhirió Ginsburg. 
La circunstancia de que Justice Souter hubiera disentido del judgment de la Corte invita a pensar en la debilidad del logro de Justice O'Connor en Erie $^{40}$. Veamos por qué ${ }^{41}$.

Tal vez en su afán por atraer la firma de Justice Souter y lograr una opinion sólida en Erie, Justice O'Connor — encargada, como vimos, de escribir la opinion for the Court- se reclinó expresamente en el voto de aquel en Barnes. En efecto, O'Connor "compró" el rationale de los efectos secundarios, que había usado Souter cuando en Barnes decidió escribir por separado, recordemos con sus palabras, para apoyar su voto "no en la posible suficiencia de los pareceres morales de la sociedad [...], sino en el interés sustancial del Estado en combatir los efectos secundarios" ${ }^{42}$.

¿Acaso no es esto revelador? La pluralidad de Barnes se apoyaba en la moralidad pública: este era el "interés importante o sustancial" que justificaba la restricción de conducta protegida por la Primera Enmienda ${ }^{43}$. En cambio, una pluralidad casi idéntica, al votar ahora

${ }^{40}$ El caso City of Los Angeles v. Alameda Books, 535 U.S. 425 (2002), al que me referiré más abajo (en 2.3), podría servir para confirmar la endeblez de lo logrado en Erie v. Pap's, en la medida en que en Alameda (un caso con cierta analogía relevante, como veremos), el propio Souter aglutinó en disidencia a Justices Stevens, Breyer y Ginsburg.

${ }^{41}$ Más allá de lo que explico en el texto, es revelador de la debilidad de este precedente el hecho de que cuando el caso volvió al tribunal de la instancia anterior (la Suprema Corte de Pennsylvania), este no se sintió obligado por los argumentos de la pluralidad de Erie v Pap's, como surge del caso conocido como Pap's II, en el cual el a quo insistió en la invalidez de la ordenanza. Véase Pap's vs Erie, del 19 de diciembre de 2002, disponible en http://caselaw.findlaw.com/pa-supreme-court/1461637.htm 1\#footnote_ref_11, visitado por última vez el 7 de junio de 2016.

42 Barnes, 582, voto concurrente de Souter. En Erie, 291, la pluralidad recordó estas palabras de Justice Souter en Barnes: "prima facie el interés gubernamental en combatir la prostitución y otras actividades criminales no está en absoluto relacionado inherentemente con la [libertad de] expresión" (con cita de Barnes, 585, voto concurrente de Souter).

${ }^{43}$ Barnes, 569 y sus citas. Contra, Cicchino, quien considera que en Barnes solo Justice Scalia apela a argumentos de moralidad pública en sentido estricto. La pluralidad, en cambio, "menciona en diversas ocasiones el interés del estado en promover la moral pública pero siempre en conjunción con el interés de bienestar público relacionado con el orden social o público". Cicchino, ps. 169-170. La consideración de este autor naufraga porque la tajante distinción entre argumentos de moralidad pública y de bienestar público, ensayada por Cicchino, es una distinción que la pluralidad de Bar- 
Moralidad pública y efectos secundarios en la jurisprudencia reciente...

en Erie no menciona en momento alguno la moralidad pública. En vez, la nueva pluralidad afirma, en línea "Souterística", que

la ordenanza prohibitiva de la desnudez pública apunta a combatir el crimen y otros efectos secundarios negativos causados por la presencia de establecimientos de entretenimiento para adultos como Kandyland y no a suprimir el mensaje erótico transmitido por este tipo de baile desnudo. Dicho de otro modo, la ordenanza no intenta regular los efectos primarios de la expresión, i.e. el efecto que mirar baile desnudo erótico causa en la audiencia que lo mira, sino más bien los efectos secundarios, como los impactos en la salud, la seguridad y el bienestar [welfare] públicos $[\ldots]^{44}$.

Compárese, por cierto, esta línea "Souterística" con el approach de Scalia en el propio Erie, donde dicho juez no siente la necesidad

que siente la Corte [i.e. la pluralidad, por su lado, y Justice Souter, por el suyo], de identificar ciertos 'efectos secundarios' asociados con el baile desnudo, cuya eliminación la ciudad estaría autorizada a buscar. [...] El tradicional poder del gobierno de promover las buenas costumbres [good morals] y la aceptabilidad del juicio tradicional (si Erie decide adoptarlo) de que el baile público desnudo es en sí mismo inmoral, no han sido derogados por la Primera Enmienda ${ }^{45}$.

Podría pensarse que Justice Souter logró por fin que prevaleciera la posición que había sostenido en Barnes, pues fue adoptada en Erie por una pluralidad de cuatro Justices que, con la suma de su parecer

nes no adopta en momento alguno —además de ser artificial si no arbitraria, como explicaré en la Conclusión-.

${ }^{44}$ Erie, 291, voto de la pluralidad.

${ }^{45}$ Erie, 310, concurrencia de Scalia, énfasis en el original. Justice Scalia reiteró esta posición en City of Los Angeles v. Alameda Books, 535 U.S. 425, 443-444 (2002). Véase la sección 2.3 infra. 
concorde, constituyen una especie de mayoría ${ }^{46}$, siquiera exigua, en torno del rationale de los efectos secundarios. Cuadra evaluar, para determinar el acierto de esta afirmación, la importancia de la mencionada omisión de la pluralidad de Erie respecto de la moralidad pública: ¿cómo ha de leerse la opinion de Justice O’Connor?; ¿supone une simultánea voluntad, semejante a la expresada por Justice Souter en Barnes, de no apoyarse en los "pareceres morales de la sociedad"?; ¿implica Erie el abandono de la doctrina recordada por la pluralidad en Barnes - y compartida, en su voto en esta última causa, por Justice Scalia - en el sentido de que la moralidad pública cumple un rol importante en la justificación de restricciones a ciertos tipos de expresión constitucionalmente protegidos?

\section{II.3 El caso Alameda (2002)}

El caso Erie admite dos lecturas. En un extremo de mayor importancia, puede sostenerse que Justice O'Connor dio un golpe de timón consistente en el efectivo abandono del rationale de la moralidad pública en el ámbito de la Primera Enmienda. También existe una lectura alternativa de Erie, según la cual el cambio que este fallo supuso respecto de Barnes es de una importancia menor: el cambio tendría que ver más bien con circunstancias coyunturales, relacionadas con el procedimiento y las alegaciones de las partes en Erie. Ergo, el supuesto "golpe de timón" no habría existido y el rationale de la moralidad pública habría sobrevivido la prueba. No es esta la ocasión de detenernos en estas dos posibles lecturas de la relación entre el fallo posterior y el anterior ${ }^{47}$. Más importante para mis finalidades hoy es, por un lado, constatar cuál fue el curso de la jurisprudencia de la Corte de los Estados Unidos luego del año 2000; y, por otro, comparar tentativamente

\footnotetext{
${ }^{46}$ No es una mayoría en sentido estricto porque, como ya se dijo, Justice Souter no suscribió la opinion de Justice O'Connor sino que votó por separado.

${ }^{47} \mathrm{Me}$ he ocupado de esta lectura comparativa detallada en mi libro Poder de policía y moralidad pública, Ábaco, Buenos Aires, 2004, capítulo V.
} 
Moralidad pública y efectos secundarios en la jurisprudencia reciente...

los dos rationales para determinar cuál es superior, si es que acaso son incompatibles.

En cuanto a lo primero, de una búsqueda de jurisprudencia resulta que solamente en una ocasión la Corte volvió a ocuparse de un asunto análogo al abordado en Barnes y en Erie. Ello ocurrió en el año 2002, en el caso City of Los Angeles v. Alameda Books, en el que se encontraba en discusión la validez de una ordenanza prohibitiva de la existencia de más de un negocio de "entretenimiento para adultos" en un mismo edificio ${ }^{48}$.

Una pluralidad, liderada nuevamente por Justice O'Connor, a quien se sumaron Rehnquist, Scalia y Thomas, sostuvo que la ordenanza era prima facie válida a la luz del test de los efectos secundarios. Esta nueva (y extraña) pluralidad citó como autoridad, en refuerzo de la tesis de que atender los efectos secundarios constituye un interés "sustancial o importante", el voto de la pluralidad en Erie v. Pap's.

Justice Scalia, además de firmar el voto de la pluralidad — cosa que no había hecho en Erie- agregó una brevísima concurrencia separada para aclarar - como sí lo había hecho en Erie- que "en un caso como este nuestras tradiciones relacionadas con la Primera Enmienda tornan bastante innecesario el análisis de los efectos secundarios. La Constitución no impide a aquellas comunidades que deseen hacerlo, regular o, más aún, suprimir enteramente, el negocio de ofrecer sexo [the business of pandering sex]"49.

Cabe agregar que Justice Kennedy, a pesar de no compartir la opinion de la pluralidad en Alameda Books adhirió al judgment propuesto por Justice O'Connor y aportó así el quinto voto decisivo.

Votaron en disidencia Stevens, Ginsburg y Breyer, liderados por... Justice Souter. Pienso que este liderazgo, así como los hechos de que Justice Kennedy — que había integrado las pluralidades de Barnes y Erie- no haya aceptado unirse en Alameda Books a la opinion de la

48535 U.S. 425 (2002). Los hechos no son tan análogos respecto de los de Barnes y Erie, como lo son los hechos de estos dos entre sí; pero son suficientemente análogos, me parece, bien leídos.

49 Alameda, 443-444, del voto concurrente de Scalia. 
pluralidad, y de que Justice Breyer haya integrado el bando disidente, señalan una tendencia no muy favorable al mantenimiento del rationale de la moralidad pública, y otra bastante favorable a la aceptación del test de los efectos secundarios - al menos en esta área del Derecho Constitucional estadounidense- - Veamos ahora cómo se relacionan estos dos rationales entre sí.

\section{III. ¿Moralidad pública vs efectos secundarios?}

\section{III.1 Moralidad pública}

Para poder abordar la relación entre "moralidad pública" y "efectos secundarios" necesitamos primero una definición tentativa de ambos lo que a veces se llama, didácticamente, "a working definition"-. Con tal definición en mano, debería resultar más claro qué se quiere decir cuando se afirma que una ley restrictiva de libertades o derechos constitucionales es válida (o inválida) cuando promueve la moralidad pública.

Si bien la veracidad de la definición que daré es contingente al Derecho Constitucional estadounidense, también es cierto que términos y conceptos de índole transversal, como "moralidad pública", son también usados en muchos otros sistemas de Derecho Constitucional modernos. Ergo, tanto las definiciones como las conclusiones a las que arribe también pueden ser ciertas, mutatis mutandis, para esos otros sistemas, y no solo para el estadounidense.

De la moral pública, cabe decir lo mismo que del poder de policía: "a pesar de estar en uso constante y ser indispensable en el vocabulario del Derecho Constitucional estadounidense, ha permanecido sin una definición autorizada o generalmente aceptada" ${ }^{50}$. La referencia al poder de policía no es aleatoria ya que la aparición de la moral pública

\footnotetext{
${ }^{50}$ Freund, E., The Police Power. Public Policy and Constitutional Rights, Callaghan \& Company, Chicago, 1904; reimpresión, Arno Press, New York, 1976, p. iii. La doctrina constitucional tampoco suele definir la moral pública. A lo sumo, se generan catálogos de los distintos problemas que suelen agruparse bajo el título "moralidad pública".
} 
Moralidad pública y efectos secundarios en la jurisprudencia reciente...

en el Derecho Constitucional estadounidense (al igual que en otros) suele ir de la mano de aquel: la moralidad pública es como una especie del género poder de policía ${ }^{51}$.

Cabe hacer una digresión preliminar de índole terminológica. Tanto las leyes de policía en materia de moralidad pública (las "morals laws", así llamadas ${ }^{52}$ ) como la jurisprudencia pertinente se refieren indistintamente a public morals, public morality, morals, y morality. En efecto, el estudio de los materiales norteamericanos tempranos lleva a concluir que las diversas "autoridades" (leyes, jurisprudencia, doctrina) usan indistinta e intercambiablemente los cuatro términos mencionados precedentemente ${ }^{53}$. Lo que sí parece haber siempre, aun cuando no siempre se refleje en la terminología, es un contraste con la "moral privada". En otras palabras - y esto es sustancialmente válido también respecto de las fuentes vigentes hoy en día - no se asigna importancia en el discurso jurídico ordinario al calificativo public (en las expresiones public morals y public morality), aunque esta indulgencia terminológica, insisto, no se traduzca en un desprecio de la distinción "público-privado" 54 .

La salvedad es acertada pues, más allá de cuestiones terminológicas, la equiparación total de "moral" y "moral pública" en cuanto realidades constituiría un error. Como expresa Wolfe, "[m]oralidad pública, tal como se usa convencionalmente ese término, no puede ser igualada a moralidad per se, porque ello incluiría demasiado. Moralidad 'pública' es normalmente usada como un término delimitador" 55 .

${ }^{51}$ He explicado esto con más detenimiento en: Legarre, S., "The Historical Background of the Police Power" 9 University of Pennsylvania Journal of Constitutional Law 745, 2007, sección VI.

${ }^{52} \mathrm{El}$ ya citado Freund consideraba que las prácticas reguladas por las morals laws podían agruparse en tres grandes títulos o rubros: el juego, las bebidas alcohólicas y la inmoralidad sexual. Freund, op. cit., nn. 187 ss., pp. 172 ss.

${ }^{53}$ Materiales comparados permiten arribar a pareja conclusión. Véase, por ejemplo, el lenguaje de los artículos 8 a 11 de la Convención Europea de Derechos Humanos.

${ }^{54}$ Henkin, L., "Morals and the Constitution: the Sin of Obscenity", 63 Columbia Law Review 391, 1963, p. 403: "Los casos hablan de 'moral' [morals] y de 'moral pública' [public morality] intercambiablemente".

55 Wolfe, op. cit., pág. 65. 
Otra salvedad me parece necesaria: hay que distinguir entre una dimensión "subjetiva" y otra "objetiva" de la moral pública. Las dos existen en el Derecho Constitucional, aunque en el Derecho Constitucional estadounidense durante años se le dio preeminencia a la primera sobre la segunda, lo que constituye, a mi juicio, algo problemático.

Resumidamente, según el concepto que reduce la moral pública a su dimensión subjetiva, es contrario a la moral pública lo que una mayoría (típicamente de una legislatura) dice que es contrario a la moral pública. Razonamientos como el infaustamente estampado en el caso Bowers v. Hardwick, constituyen un buen ejemplo. Allí, el Tribunal consideró suficiente para sostener la validez de una ley que prohibía la sodomía, "la presunta creencia de una mayoría del electorado de Georgia de que la sodomía [...] es inmoral e inaceptable"56. Ello sería tanto como afirmar: "Basta, en el plano público, que una mayoría diga que algo es inmoral para que sea ipso facto inmoral". No comparto.

Para que la moralidad pública esté realmente comprometida debe existir, en primer lugar, una conducta verdaderamente inmoral. Se trata de un parámetro objetivo, fruto de una argumentación racional: por tales y cuales razones tal conducta es inmoral. Como toda argumentación, a veces podrá fracasar - llevar a un juicio equivocado-; pero esa es otra historia, que supone la existencia de la verdad en el plano práctico.

Que la acción sea tradicionalmente tenida por inmoral o que sea reprobada por una mayoría legislativa, son pautas subjetivas que, de cara a una correcta definición de la moral pública, solo son relevantes cuando constituyen una consecuencia del hecho objetivo de la inmoralidad en cuestión: porque la conducta es inmoral, fue tradicionalmente tenida por inmoral o reprobada por una mayoría legislativa. Si, en cambio, la reprobación moral no se correspondiera con una verdadera inmoralidad, constituiría un error afirmar que la legislación que

56478 U.S. 186, 196 (1986). Este fallo fue dejado sin efecto en 2003 por el caso Lawrence v. Texas 539 U.S. 558. 
Moralidad pública y efectos secundarios en la jurisprudencia reciente...

incorporase dicha reprobación promovería la moralidad pública ${ }^{57}$. Lo que promovería, en todo caso, sería una cierta tradición o la voluntad de una determinada mayoría que, despegada de verdaderas razones, puede consistir en un verdadero capricho.

Tanto las tradiciones como las mayorías pueden estar equivocadas y, como atestigua la historia, a veces gravemente equivocadas. Por ello, cuando se trata de evaluar la validez (moral y constitucional) de la legislación en materia de moralidad pública no hay que frenarse en la dimensión subjetiva: el mero hecho de que una tradición o una mayoría legislativa hayan considerado inmoral cierta conducta. Esto constituye un indicio de validez y puede ser el primer paso del análisis. Pero hay que inquirir más allá y discernir si el juicio tradicional o mayoritario se basa en razones o en caprichos. De lo contrario no habría manera de distinguir entre normas que promueven la moral pública y normas que, so capa de moral pública, imponen verdaderas inmoralidades. Un ejemplo de lo segundo es el derecho nazi, que incorporó la reprobación de una raza por parte de una mayoría legislativa. Lo que promovía la legislación racista no era la moralidad pública — aunque pudiera alegarse ello falazmente - sino precisamente lo contrario: la inmoralidad pública.

Otra reflexión que se impone a esta altura del discurso es que de la afirmación de que una conducta ofende la moralidad pública no se sigue ineludiblemente que aquella deba ser prohibida por el gobierno del estado. La genuina inmoralidad del acto prohibido es condición necesaria pero no suficiente de la legitimidad de su prohibición ${ }^{58}$. Pues como ya lo sostenía Tomás de Aquino en el medioevo, la ley no debe

${ }^{57}$ En sentido semejante: George, R. P., Para hacer mejores a los hombres: Libertades civiles y moralidad pública, Ediciones Internacionales Universitarias, Madrid, 2002; traducción de Making Men Moral: Civic Liberties and Public Morality, Clarendon Press, Oxford y New York, 1993, Capítulo 2. Lo que he llamado exigencias objetivas de la moralidad pública lleva a este autor a rechazar — con razón, a mi juicio- la justificación conservadora de la legislación en materias morales defendida por Lord Devlin en su célebre debate con el Profesor Hart: "En contra de Devlin, mantengo que si un acto moralmente controvertido no es, de hecho, inmoral entonces no puede justificarse su prohibición legal". George, op. cit., pág. 13.

${ }^{58}$ Nuevamente remito a George, op. cit., p. 14. 
prohibir todos los vicios sino solamente los más graves ${ }^{59}$. Razones de prudencia exigen (moralmente) que algunas inmoralidades públicas deban ser toleradas. Es una delicada tarea del legislador discernir cuándo la prohibición de una determinada conducta que afecta la moral pública traerá consecuencias peores que su tolerancia.

En resumen, lo que se debe querer decir cuando se afirma que una ley restrictiva de libertades o derechos constitucionales es válida "cuando promueve la moralidad pública" es que constituye un fin constitucionalmente legítimo de la ley promover aquello que un legislador razonable considera conducente al verdadero bien de la comunidad en su dimensión moral - y no cualquier decisión de cualquier mayoríaPor extensión, se dicen válidas las manifestaciones legislativas que tienden a excluir o limitar las manifestaciones públicas de aquello que un legislador razonable considera verdaderamente inmoral.

En un sistema constitucional dado, lo precedente será cierto en la medida en que las restricciones y arreglos institucionales en concreto permitan legislar en pro de la moral pública (pues, por hipótesis, el constituyente podría decidir excluir esta posibilidad — dicho esto con independencia del juicio que tal exclusión merecería-). Así, en el derecho constitucional estadounidense tradicional, entendido a la luz de la teoría desarrollada en este trabajo, la promoción de la verdadera moralidad pública constituía tanto un interés sustancial e importante, que brindaba al gobierno del estado autoridad constitucional para legislar, como también, a fortiori, una base racional suficiente para ese tipo de legislación. En la "Era Moderna", en cambio, la promoción de la verdadera moralidad pública, si bien otorga una base racional suficiente para la "morals legislation", no sobrevive, en principio, el escrutinio estricto requerido por los derechos fundamentales, por no considerársela, en ese contexto, un interés estatal impostergable.

${ }^{59}$ Suma Teológica, I-II q. 96 a. 2c: "[...] por la ley humana no se prohíben todos los vicios, de que se abstienen los virtuosos, sino solo los más graves, de los que es posible que se abstenga la mayor parte de la multitud [...]". 
Moralidad pública y efectos secundarios en la jurisprudencia reciente...

\section{III.2 Efectos secundarios}

Munidos de esta caracterización aproximada de la "moral pública" veamos ahora qué son los "efectos secundarios"60, a fin de juzgar acerca de la relación entre ambos, incluida la posible superioridad de uno de esos estándares sobre el otro. La caracterización que necesitamos de los "efectos secundarios" se ceñirá al uso de este concepto en el campo del derecho constitucional bajo estudio - las restricciones al baile desnudo-, aun cuando el tema de estos efectos lo excede ampliamente y tiene una importancia capital en la ética.

En el contexto estudiado, se distingue entre los efectos primarios de una determinada "expresión" (incluida la "conducta expresiva"61, como el baile desnudo) y sus efectos secundarios. El efecto primario de dicho baile es, en palabras de la pluralidad de Erie, "el efecto que mirar baile desnudo erótico causa en la audiencia que lo mira"62. La misma pluralidad de Erie contrasta este efecto primario de la expresión con "efectos secundarios, como los impactos en la salud, la seguridad y el bienestar [welfare] públicos"63.

En el voto de Justice Souter en Barnes, ya se nos ofrecía una concreción de la idea general. Souter recordaba en Barnes que Indiana había defendido el "interés sustancial del Estado en combatir los efectos

${ }^{60}$ Cabe adelantar que no son pocos los autores estadounidenses que, por distintas razones (y casi siempre sin que esto implique una aceptación de la moralidad pública como alternativa), resisten la doctrina de los efectos secundarios en el Derecho Constitucional. Véase, por ejemplo, Fee, J., "The Pornographic Secondary Effects Doctrine", Alabama Law Review, 60, 2009, pp. 291-293; Chemerinsky, E., "Content Neutrality as a Central Problem of Freedom of Speech: Problems in the Supreme Court's Application", Southern California Law Review. 49, 2000, pp. 59-61; Kagan, E., "Private Speech, Public Purpose: The Role of Governmental Motive in First Amendment Doctrine", University of Chicago Law Review, 63, 1996, pp. 413-490; Stone, G. R., "Content-Neutral Restrictions”, University of Chicago Law Review, 54. 46, 1987, pp. 115-17.

${ }^{61}$ La "conducta expresiva" es considerada "expresión" (speech) por la Corte Suprema de los Estados Unidos, si se dan ciertas circunstancias. Véase Texas v. Johnson, 491 U.S. 397, 404 (1989).

62 Erie, 291, opinion de la pluralidad.

${ }^{63}$ Erie, 291, opinion de la pluralidad. 
secundarios de los establecimientos de entretenimiento para adultos"64. Según el Estado, el salón Kitty-Kat "favorece la prostitución, incrementa las ofensas sexuales y atrae otras actividades criminales" 65 . La pluralidad de Erie mencionó consecuencias parecidas en su lista de los efectos que, según el Estado de Pennsylvania, pueden causar establecimientos de shows de desnudo en vivo, "en la medida en que proveen una atmósfera que favorece la violencia, el acoso sexual, la embriaguez pública, la prostitución, la difusión de enfermedades venéreas" 66 .

Noto que no parece casual que estos efectos secundarios ocurran como resultado de la realización del efecto primario (a saber, erotizar a la audiencia). Parece cierto lo que sin duda lo es de otros efectos secundarios: que estos efectos son previsibles y no del todo sorprendentes, una vez que se intenta buscar el efecto primario. Lo que me lleva al siguiente paso en el discurso: en el razonamiento de Justice Souter en Barnes se encuentra implícito, y en el de la pluralidad en Erie explícito, que estos efectos secundarios son "deletéreos" y "adversos", términos, ambos, con una connotación negativa. A tal punto que "deletéreo" significa "mortífero", "venenoso" 67.

A mi modo de ver, los efectos secundarios mencionados en las dos listas (la de Justice Souter y la de la pluralidad) se entienden mejor como dañosos ${ }^{68} \mathrm{y}$, sobre todo, como mortíferos o venenosos, solamente si se adopta una perspectiva moral. De lo contrario (y más allá de su eventual ilegalidad, que es contingente) resulta difícil calificar así a la prostitución, por ejemplo. Y ello nos reconduce al rationale de la moralidad pública. $\mathrm{Y}$ al recuerdo de que la afirmación de la inmoralidad de la conducta de

${ }^{64}$ Barnes, 582, voto concurrente de Souter.

65 Barnes, 582, voto concurrente de Souter, con cita del Brief for Petitioners.

${ }^{66}$ Erie, 290, opinion de la pluralidad, con cita del preámbulo de la ordenanza de Erie. La cita completa, con uso de las expresiones "efectos adversos" y "efectos deletéreos", es: "La ordenanza de Erie se dictó para limitar el reciente incremento en la ciudad de shows de desnudo en vivo, en razón de sus efectos adversos sobre la salud, la seguridad y el bienestar [welfare] públicos en la medida en que proveen una atmósfera que favorece la violencia, el acoso sexual, la embriaguez pública, la prostitución, la difusión de enfermedades venéreas y otros efectos deletéreos".

${ }^{67}$ Cfr. el Diccionario de la Lengua Española, disponible en www.rae.es.

${ }^{68}$ La palabra usada en inglés en este caso es "deleterious", que significa "dañoso". 
Moralidad pública y efectos secundarios en la jurisprudencia reciente...

cuyos efectos se trata no va necesariamente de la mano de su prohibición (como lo ilustra el supuesto del baile desnudo, al cual cabría acaso aplicarle la ya estampada sentencia de Tomás de Aquino: la ley no debe prohibir todos los vicios sino solamente los más graves ${ }^{69}$ ).

De hecho, el rationale de la moralidad pública es totalmente compatible con el de los efectos secundarios y justifica mejor el uso de un argumento basado en este tipo de efectos. Pues esa "no casualidad" antes aludida (con referencia a la relación entre tales efectos y el baile desnudo) se debe precisamente a que de una conducta alegadamente inmoral en el plano público pueden esperarse efectos alegadamente inmorales en el plano público. Por ello, para seguir con nuestro ejemplo, la argumentación de los estados de Indiana y Pennsylvania de que el baile desnudo irrestricto afecta la moralidad pública no se ve perjudicada sino reforzada por el argumento de que ese tipo de baile irrestricto acarrea efectos secundarios nocivos ${ }^{70}$.

¿Por qué, entonces, se insiste tanto en los efectos secundarios y menos (al parecer, cada vez menos) en la moralidad pública? ¿Por qué este eclipse - esta aparente sustitución de la moralidad pública por los efectos secundarios- en el voto de Souter en Barnes y en el de la pluralidad en Erie y Alameda ${ }^{71}$ ? Y, en línea afín, ¿por qué la adversidad a la moralidad pública (a favor de los efectos secundarios), presente en la literatura académica predominante ${ }^{72}$ ?

${ }^{69}$ Suma Teológica, I-II q. 96 a. 2c, op. cit.

${ }^{70}$ Algunos críticos del rationale de la moralidad pública ven esto claro y por eso se resisten también al rationale de los efectos secundarios. Véase, Goldberg, S., "Morals-Based Justifications for Lawmaking: Before and After Lawrence v. Texas", Minnesota Law Review, 88, 2004, pp. 1233-1307

${ }^{71}$ En Alameda el juez Souter dice con claridad: "Al examinar pretensiones de que existen relaciones causales entre negocios de entretenimiento para adultos y un aumento de efectos secundarios (distintos del mero desacuerdo [con la existencia de dichos negocios]) [...] es necesario enfatizar el carácter empírico de la demostración disponible [...]. Y precisamente porque este tipo de prueba está al alcance de la mano, los tribunales en ejercicio del control de constitucionalidad deben ser cautos cuando el gobierno apela, no a pruebas, sino a un sentido común acrítico [...]". City of Los Angeles v. Alameda Books, 535 U.S. 425, 458-459 (2002), disidencia de Souter, énfasis agregado.

${ }^{72}$ A mero título de ejemplo, Henkin sostiene que solo deben aceptarse en el discurso constitucional argumentos que estén "[...] sujetos a la lógica y a la comprobación 
Acaso se deba a la sensación de que los efectos secundarios son de naturaleza empírica (sujetos, por tanto, a comprobación) mientras que la moralidad pública es de naturaleza metafísica ${ }^{73} \mathrm{o}$, incluso se sostiene $^{74}$, teológica. Esta es una sensación en parte verdadera y en parte falsa. Es verdadera en cuanto que los efectos secundarios se pueden medir: pueden ser, y son, objeto de estudios, encuestas y estadísticas, como lo muestran especialmente los casos Erie y Alameda. En ellos (así como en el voto de Souter en Barnes) los entes reguladores intentan demostrar, por ejemplo, que como consecuencia de la instalación de un establecimiento para adultos en un barrio, cayeron los precios de las propiedades vecinas; o que en las inmediaciones de un establecimiento se registran más delitos que en otras zonas de la ciudad.

Este tipo de demostración no es posible, al parecer, con la moralidad pública, salvo que se la reduzca a su elemento subjetivo. Si se tratara de medir preferencias mayoritarias y la inmoralidad pública fuera sinónimo de desaprobación popular, en esa medida la "moralidad pública" también sería medible (mediante encuestas y estudios de opinión). Pero ya hemos visto en este trabajo que reducir la moralidad pública a su elemento subjetivo constituye un error y peca de insuficiencia; y el elemento objetivo es, efectivamente, de naturaleza "metafísica" (solo en el sentido de "no medible"): la argumentación de que tal conducta es mala para una comunidad es un tipo de argumentación que no se conduce eficazmente con las herramientas de un laboratorio.

inherentes a la razonabilidad y a la racionalidad" y define a las morals laws como aquéllas "que reflejan alguna moral tradicional que carece de una auténtica finalidad social de proteger las personas o propiedades de otros". Henkin, cit., ps. 406 y 402 respectivamente; énfasis en el original. En línea parecida, según Cicchino serían ejemplo de leyes "racionales" las basadas en argumentos que favorecen la restricción de una actividad en razón de sus efectos secundarios dañosos (y no en razón de una supuesta violación de la moral pública, pues esto llevaría a afirmaciones dogmáticas, inmunizadas de toda refutación experimental). Cicchino, op. cit., pág. 149 y 162.

${ }^{73}$ Véase, Gey, S.G., "Is Moral Relativism A Constitutional Command?", Indiana Law Review, 70, 195, pág. 331.

${ }^{74}$ Cicchino, op. cit., pp. 173-178. "El efecto de las meras aserciones de moralidad pública en el discurso cívico es idéntico al de las aserciones sectarias o teológicas: frenan el diálogo racional" (pág. 176). 
Moralidad pública y efectos secundarios en la jurisprudencia reciente...

Mas la sensación de que con los efectos secundarios uno se encuentra al abrigo de toda argumentación que no sea empíricamente verificable es sobre todo falsa porque, como ya insinué, el argumento de los efectos secundarios solo selecciona algunos efectos secundarios y estos son los que califica de dañosos, venenosos o mortíferos. Es decir que, en definitiva, el camino empírico mantiene la necesidad del camino "metafísico" (que yo llamaría más propiamente "filosófico" y, dentro de la filosofía, "moral" o "ético").

\section{Conclusión}

No es cierto, como lo sostiene el profesor Cicchino, que los efectos secundarios "son precisamente los tipos de efectos empíricos sobre el bienestar público respecto de los cuales los argumentos de moralidad pública [...] están desconectados"75. Más bien es exactamente al revés: el argumento que apela a los efectos secundarios de una determinada conducta, para justificar su restricción, está plenamente conectado con el argumento en torno de la moralidad (pública) de dicha conducta (y de sus efectos).

Por ello, es artificial si no incluso arbitraria la presentación que hace Cicchino de los argumentos de moralidad pública, como si se los pudiera separar de modo tajante. Y al no existir una diferencia tajante entre ellos (al ser más bien, conceptos complementarios y compatibles) tampoco tiene sentido enfrentarlos o contraponerlos.

Por la misma razón, tampoco tiene sentido adjudicar una excesiva relevancia al hecho de que en algún caso (Souter en Barnes) o en otro (la pluralidad en Erie y Alameda) los jueces pongan el énfasis en los

75 Ibidem, pág. 170. Tampoco es cierto, por tanto, que los argumentos de moralidad pública "defienden una ley mediante la afirmación de un interés gubernamental legítimo en la prohibición o el favorecimiento de cierta conducta humana, sin ninguna conexión empírica con bienes distintos del alegado bien de eliminar o incrementar, según sea el caso, la conducta en cuestión”. Cicchino, op.cit., pp. 140-141. Pues, como se explica en el texto, la conexión existe. 
efectos secundarios antes que en la moralidad pública ${ }^{76}$. Si se quiere entender bien estos efectos, cualquier énfasis de ese tipo dejará intacta la centralidad de la moralidad pública.

\section{Bibliografía}

Chemerinsky, E., "Content Neutrality as a Central Problem of Freedom of Speech: Problems in the Supreme Court's Application", Southern California Law Review. 49, 2000, pp. 59-61.

Cicchino, P. M., "Reason and the Rule of Law: Should Bare Assertions of 'Public Morality' Qualify as Legitimate Government Interests for the Purposes of Equal Protection Review?", Georgetown Law Journal 87, 139, 1998, p. 170.

Fee, J., "The Pornographic Secondary Effects Doctrine", Alabama Law Review, 60, 2009, pp. 291-293.

Freund, E., The Police Power. Public Policy and Constitutional Rights, Callaghan \& Company, Chicago, 1904; [reimpresión, Arno Press, New York, 1976].

George, R. P., Para hacer mejores a los hombres: Libertades civiles y moralidad pública, Ediciones Internacionales Universitarias, Madrid, 2002.

Goldberg, S., "Morals-Based Justifications for Lawmaking: Before and After Lawrence v. Texas", Minnesota Law Review, 88, 2004, pp. 1233-1307.

Henkin, L., "Morals and the Constitution: the Sin of Obscenity", 63 Columbia Law Review 391, 1963.

Kagan, E., "Private Speech, Public Purpose: The Role of Governmental Motive in First Amendment Doctrine", University of Chicago Law Review, 63, 1996 413-490

Legarre, S., "The Historical Background of the Police Power" 9 University of Pennsylvania Journal of Constitutional Law 745, 2007. 
Moralidad pública y efectos secundarios en la jurisprudencia reciente...

Legarre, S., Poder de policía y moralidad pública, Ábaco, Buenos Aires, 2004.

Stone, G. R., "Content-Neutral Restrictions", University of Chicago Law Review 54, 46, 1987, pp. 115-17.

Wolfe, C., "Public Morality and the Modern Supreme Court", 45 American Journal of Jurisprudence 65, 2000, pág. 71. 